\title{
Inhibition of $\mathrm{CK} 2$ binding to BMPRIa induces $\mathrm{C2C12}$ differentiation into osteoblasts and adipocytes
}

\author{
Oleksandra Moseychuk • Hemanth Akkiraju • \\ Joyita Dutta • Alex D'Angelo • Beth Bragdon • \\ Randall L. Duncan • Anja Nohe
}

Received: 15 November 2012 / Accepted: 12 March 2013 / Published online: 1 May 2013

(C) The International CCN Society 2013

\begin{abstract}
BMP2 is a growth factor that regulates the cell fate of mesenchymal stem cells into osteoblast and adipocytes. However, the detailed signaling pathways and mechanism are unknown. We previously reported a new interaction of Casein kinase II (CK2) with the BMP receptor type-Ia (BMPRIa) and demonstrated using mimetic peptides CK2.1, CK2.2 and CK2.3 that the release of CK2 from BMPRIa activates Smad signaling and osteogenesis. Previously, we showed that mutation of these CK2 sites on BMPRIa (MCK2.1 (476S-A), MCK2.2 (324S-A) and MCK2.3 (214S-A)) induced osteogenesis. However, one mutant MCK2.1 induced osteogenesis similar to overexpression of wild type BMPRIa, suggesting that the effect of this mutant on mineralization was due to overexpression. In this paper we investigated the signaling pathways involved in the CK2-BMPRIa mediated osteogenesis and identified a new signaling pathway activating adipogenesis dependent on the BMPRIa and CK2 association. Further the mechanism for adipogenesis and osteogenesis is specific to the CK2 interaction site on BMPRIa. In detail our data show that overexpression of MCK2.2 induced osteogenesis was dependent on Caveolin-1 (Cav1) and the activation of the Smad and mTor pathways, while overexpression of MCK2.3 induced osteogenesis was independent of Caveolin-1 without activation of Smad pathway. However, MCK2.3 induced osteogenesis via the MEK pathway. The adipogenesis induced by the overexpression of MCK2.2 in $\mathrm{C} 2 \mathrm{C} 12$ cells was dependent on
\end{abstract}

O. Moseychuk $\cdot$ H. Akkiraju $\cdot$ J. Dutta $\cdot$ A. D'Angelo

B. Bragdon $\cdot$ R. L. Duncan $\cdot$ A. Nohe

Department of Biological Sciences, University of Delaware,

Newark, DE 19716, USA

A. Nohe $(\bowtie)$

Department of Biology, University of Delaware, Newark, DE

19716, USA

e-mail: anjanohe@udel.edu the p38 and ERK pathways as well as Caveolin-1. These data suggest that signaling through BMPRIa used two different signaling pathways to induce osteogenesis dependent on CK2. Additionally the data supports a signaling pathway initiated in caveolae and one outside of caveolae to induce mineralization. Moreover, they reveal the signaling pathway of BMPRIa mediated adipogenesis.

Keywords BMP2 - Adipogenesis · Osteogenesis · Casein Kinase II

\section{Introduction}

Bone morphogenetic protein 2 (BMP2) is a growth factor that belongs to the TGF-beta superfamily and plays a crucial role not only during skeletal development but in processes as diverse as neurogenesis and hematopoiesis reviewed (Chen et al. 2004; Kawai et al. 1994). At the cellular level, BMP2 is a key factor regulating the cell fate of mesenchymal stem cells (MSCs) into osteoblasts, adipocytes, myocytes and chondrocytes reviewed in (Senta et al. 2009). However, the key mechanisms regulating these processes are still undetermined, especially the specificity of signals that drives the specific pathways.

The most studied BMP2-dependent signaling occurs via the BMP receptor type Ia (BMPRIa) and BMP receptor type II (BMPRII). BMP receptors are serine/threonine kinases. The type II receptors are constitutively active and activate the type I receptors by phosphorylation at the GS box (glycine/serine rich region of the BMPRIa) upon ligand binding reviewed in (Bragdon et al. 2012; Chen et al. 2004; ten Dijke et al. 1993). We previously reported an interaction of Casein Kinase II (CK2) with BMPRIa (Bragdon et al. 2010). CK2 is a highly conserved, ubiquitously expressed enzyme with more than 
300 substrates that affects cell growth, proliferation, differentiation, apoptosis and tumorigenesis reviewed in (Duncan and Litchfield 2008). CK2 interacts with BMPRIa at three potential sites: at amino acid residues 213-217, 324-328 and 475479 , which are conserved throughout TGF-beta Type I receptor (Bragdon et al. 2010). Using peptides blocking the interaction of BMPRIa with CK2, CK2.1, CK2.2 and CK2.3, we previously showed that the Smad pathway is activated without exogenous BMP2 being necessary (Bragdon et al. 2009; 2010). Similarly, mutation of the CK2 sites on BMPRIa by exchanging S-A within one of the three potential CK2 phosphorylation sites leads to induction of osteogenesis. As we previously reported this is due to CK2 being released from BMPRIa in response to BMP2 stimulation (Fig. 1a) (Bragdon et al. 2011;2010).

Once active, the BMPRIa initiates BMP signaling at the cell membrane in distinct membrane domains such as caveolae and clathrin coated pits (CCPs) (Bragdon et al. 2009; Hartung et al. 2006; Nohe et al. 2004). It is thought that the location of the BMP receptors in distinct domains regulates specific downstream responses. Canonical Smaddependent signaling by phosphorylation of Smad1, 5 and 8 . Phosphorylated Smad1, 5 and 8 bind to Smad4 and the Smad complex translocates to the nucleus where it activates the expression of targeted genes reviewed in (Massague 1998) such as RUNX2 (Matsubara et al. 2008) or PPAR $\gamma$ (Hata et al. 2003). RUNX2 was shown to be a key regulator for osteogenesis, (Matsubara et al. 2008) while the induction of peroxisome proliferators-activated receptor $\gamma(\operatorname{PPAR} \gamma)$ is crucial for differentiation into adipocytes. PPAR $\gamma$ is dependent on the levels of CCAAT/enhancer binding protein- $\beta$ (C/EBP- $\beta$ ) (Siersbaek et al. 2010).

In the Smad-independent signaling, the $\mathrm{p} 38, \mathrm{mTOR}$ and ERK, signaling pathways are activated (Lai and Cheng 2002; Langenfeld et al. 2005) (Fig. 1b). To activate the p38 pathway, activated BMP receptor complex activates TGF- $\beta$-activated Kinase 1 (TAK1), a MAP kinase kinase kinase, and TAK binding protein 1 (TAB1). The TAK1TAB1 complex activates MAP kinase kinases, MKK3, MKK6, and MKK4, and NF-kB, MKK3 and MKK6 activates p38, a MAP kinase (Kimura et al. 2000) (Fig. 1b). AKT, a serine threonine kinase, is activated through the PI3K kinase pathways and plays a key role in multiple cellular processes such as glucose metabolism, cell proliferation, apoptosis, gene transcription and cell migration. BMP2 can also activate ERK, but the mechanism of activation is not known. ERK1/2 further activates MEK1/2 (Lou et al. 2000).

The p38 (Guicheux et al. 2003) and Smad (Hata et al. 2003) pathways were shown to be necessary for MSC differentiation; however both pathways are activated independent of the differentiation outcome. This indicates that other factors and pathways such as ERK and AKT signaling maybe are crucial determinants for the final cell fate. Another possibility lies in a protein that is not identified or not associated with these pathways (Lou et al. 2000).
Fig. 1 BMP2 signaling pathway resulting in osteogenesis or adipogenesis. a Ligand binding to BMPRIa and BMPRII results in the release of CK2, followed by phosphorylation of BMPRIa by a constitutively active BMPRII, leading to signaling. $\mathbf{b}$ Signaling via Smad1, 5, and 8 , ERK, PI3K, JNK, p38, and NF-kB results in osteogenesis. c Activation of Smad1, 5, and 8 and p38 pathways are implicated in adipogenesis

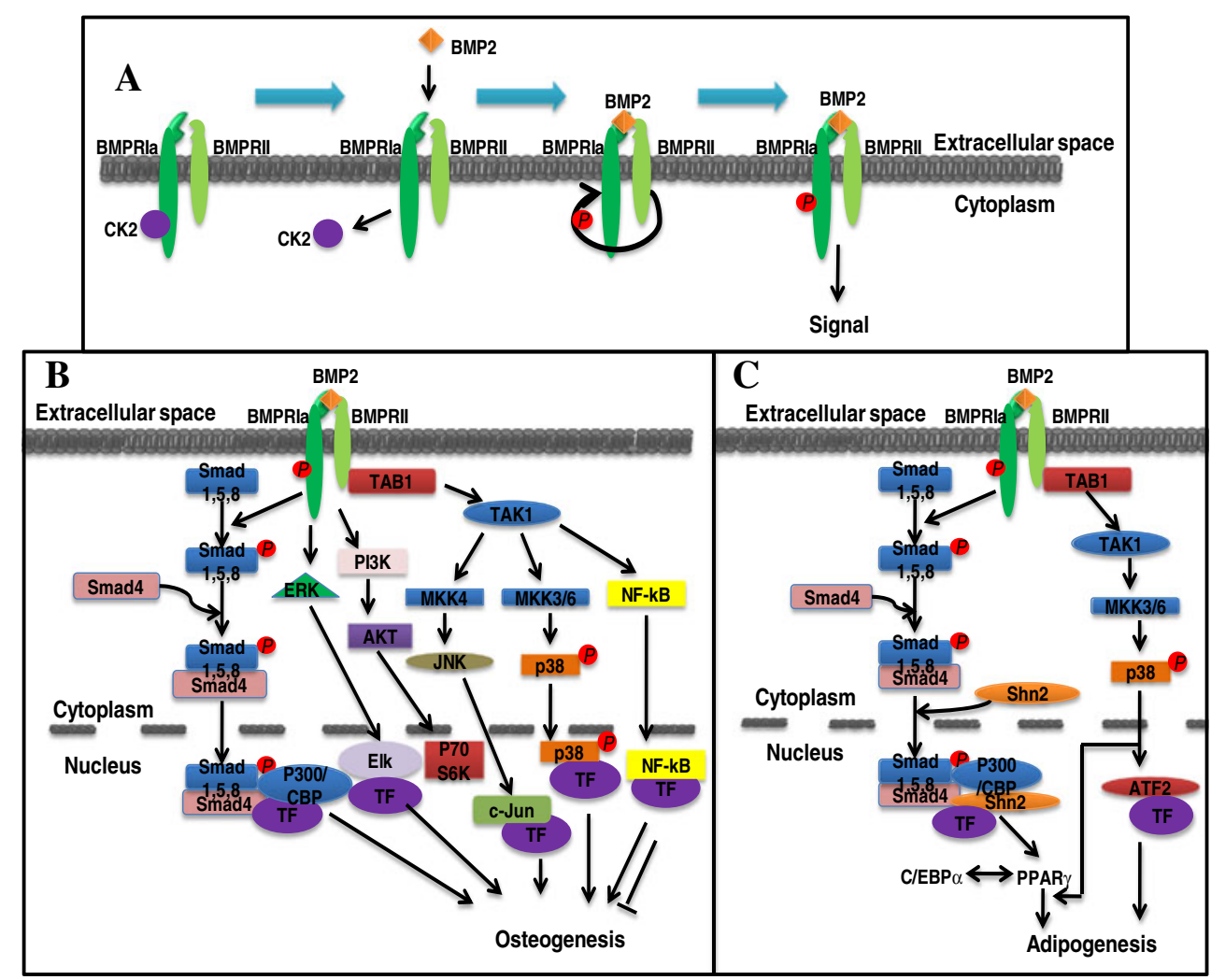


Here we show that the signaling activated by the peptides is independent of the presence of BMP2. Mutation of the CK2 phosphorylation site on BMPRIa at 213-217 (MCK2.3) led specifically to osteogenesis through the MEK/ERK pathway. Mutation of the CK2 phosphorylation site at 324-328 (MCK2.2) led to both adipogenesis and osteogenesis. Similar effects were observed by blocking CK2 from binding to BMPRIa using peptides CK2.2 and CK2.3. MCK2.2 mediated osteogenesis is mediated by Smad and mTor pathways, while adipogenesis is mediated by p38 and ERK pathways. Additionally, we show that mineralization is induced in a Caveolin-1 (Cav1) dependent and independent manner. These data reveal signaling pathways activated by BMPRIa to induce osteogenesis and adipogenesis. The data also demonstrate that both processes can be mediated through the same BMP type-I receptor.

\section{Materials and methods}

\section{Materials}

The cell line $\mathrm{C} 2 \mathrm{C} 12$ was purchased from American Type Culture Collection (Manassas, VA, USA). Recombinant BMP2 was obtained from GenScript (Piscataway, NJ, USA). Peptides, HD (control peptide containing the Antennapedia homeodomain signaling sequence), CK2.2, and CK2.3 were purchased from GenScript (Piscataway, NJ, USA). Plasmids encoding BMPRIa-RFP, BMPRIa mutants MCK2.2, and MCK2.3 constructs were subcloned and mutated by Mutagenex (Piscataway, NJ, USA). SB203580 (p38) inhibitor, PD98059 (MEK) inhibitor, and Rapamycin (mTOR) were purchased from CalBiochem (San Diego, CA).

\section{Cell culture}

Murine myoblast cells (C2C12) were grown in Dulbecco's Modified Eagle's Medium (Hy-Clone, Pittsburgh, PA) supplemented with $10 \%(v / v)$ fetal bovine serum (FBS) (Gemini Bio-Products, West Sacramento, CA), $0.5 \%(v / v)$ L-Glutamine (Cellgro, Manassas, VA) and $1 \%(v / v)$ penicillin/streptomycin (Hy-Clone, Pittsburgh, PA). Serum starved media without FBS contained Dulbecco's Modified Eagle's Medium (Hy-Clone, Pittsburgh, PA) supplemented with $0.5 \%(v / v)$ L-Glutamine (Cellgro, Manassas, VA) and $1 \%(v / v)$ penicillin/streptomycin (Hy-Clone, Pittsburgh, $\mathrm{PA})$. Non-treated $\mathrm{C} 2 \mathrm{C} 12$ cells in serum starved media simultaneously differentiate into myocytes. Media was changed every other day. 1X Trypsin (Cellgro, Manassas, VA) was used to detach cells from the flasks during cell splitting and plating.

\section{Design of CK2 peptides}

A Prosite search including patterns with a high probability of occurrence on BMPRIa yielded possible CK2 phosphorylation sites at amino acids 213-217 (SLKD), and 324-328 (SLYD). Peptides were designed with the Antennapedia homeodomain signal sequence for cellular uptake and incorporated one of these binding sites, CK2.2 (SLYD), and CK2.3 (SLKD). The peptides also included several amino acid residues flanking each side that are important for the binding of CK2 to BMPRIa, creating a total length of 29 amino acids (CK2.2 and CK2.3).

\section{Design of BMPRIa mutants lacking CK2 binding site}

Mutant constructs of BMPRIa were generated and verified by DNA sequencing by Mutagenex (Piscataway, NJ, USA). The BMPRIa sequence in the expression vector pcDNA I was subcloned into the ds RFP monomeric vector using the cloning sites Hind III and XbaI (BMPRIa-RFP). The BMPRIa subcloned into expression vector pcDNA I has previously been described (Gilboa et al. 2000). The BMPRIa mouse sequence contains two predicted CK2 phosphorylation sites, located at amino acids 213-217 (SLKD), and 324-328 (SLYD). The serine amino acid was point mutated to an alanine in each of the CK2 phosphorylation sites. The dsRED monomeric vector was obtained from Dr. Robert Sikes at the University of Delaware.

\section{Von Kossa}

$\mathrm{C} 2 \mathrm{C} 12$ cells were grown to $90 \%$ confluence in 24 well plates and serum starved overnight before treatment. Next day cells were treated as noted per individual experiment with the peptides, BMP2 or Noggin. After 7 days cells were washed with cold PBS $\mathrm{pH} 7.4$, fixed using $4 \%(w / v)$ parafolmaldehyde for $10 \mathrm{~min}$, and washed with cold PBS $\mathrm{pH} 7.4$ again to remove remnants of fixative. Von Kossa stain $5 \%(w / v)$ silver nitrate in $\mathrm{dH}_{2} \mathrm{O}$ as previously described (Bragdon et al. 2010) was applied to each well and plate was put under the UV light for 10-30 min depending on the intensity of individual UV light box (same light box was used within each set of experiments). Cells were then washed with $\mathrm{dH}_{2} \mathrm{O}$ until $\mathrm{dH}_{2} \mathrm{O}$ washed clear. Plates were allowed to dry and the mineralized area was identified by dark areas. These areas were analyzed by taking at least 20 random high magnification images of each well of treatment with a Nikon TMS automatic mode with phase 1 with a $20 \times$ objective. Data was then quantified with the use of ImageJ (NIH, Bethesda), where images were converted to 8 bit and threshold was set to the positive control. Same threshold was used for all treatments in an individual experiment. The surface area of the stain was quantified by using the 
"analyzing particles function", a function of ImageJ that can be used to calculate areas of black which represented mineralization section. All media was the same for all treatments for osteogenesis. The difference was only in the addition of the peptides or transfection of the cells.

\section{Oil Red O}

C2C12 cells were grown to $90 \%$ confluence in 24 well cell star plates from GBO and serum starved overnight before treatment. Next day cells were treated as noted per individual experiment. After 7 days, depending on the conditions of individual experiment, cells were washed with cold PBS pH7.4, fixed using $4 \%(w / v)$ paraformaldehyde for $10 \mathrm{~min}$ and washed with cold PBS pH7.4 again to remove excess fixative. Oil Red O stain was prepared by creating a stock solution consisting of $0.35 \mathrm{~g}$ of Oil Red O powder dissolved in $100 \mathrm{ml}$ of isopropanol. On the day of staining $6 \mathrm{ml}$ of stock solution was mixed with $4 \mathrm{ml}$ of $\mathrm{dH}_{2} \mathrm{O}$ which was labeled as working solution and set aside for $20 \mathrm{~min}$ after which it was filtrated through $0.22 \mu \mathrm{m}$ filter. The working solution was applied to each well for $15 \mathrm{~min}$ and washed once with $\mathrm{dH}_{2} \mathrm{O}$ for a period of $1 \mathrm{~min}$ to avoid washing off lipid droplets. Plates were allowed to dry. The area covered by lipid droplets (identified by the red stain) was analyzed by taking at least 20 random high magnification images of each well of treatment with a Nikon TMS automatic mode with phase 1. Data was then quantified with the use of ImageJ, where images were converted to 8 bit and threshold was set to the positive control. Same threshold was used for all treatments in an individual experiment. The surface area of the stain was quantified by using the "analyzing particles function", a function of ImageJ that can be used to calculate areas of dark which here is the lipid droplets. All media was the same for all treatments for adipogenesis. The difference was only in the addition of the peptides or transfection of the cells.

Co-transfection of $\mathrm{C} 2 \mathrm{C} 12$ cells

C2C12 cells were grown to $90 \%$ confluence in 24 well plates and serum starved overnight before treatment. Cells were then transfected by Turbofect (Fermentas, Glen Burnie, MD) following manufacture's procedure with $3 \mu \mathrm{g}$ DNA plasmid encoding BMPRIa, MCK2.1, MCK2.2, or MCK2.3 and 200 omole Cav1, CK2, or Smad4 (Santa Cruz Biotechnology, Santa Cruz, CA) where noted. These siRNAs were identical to those previously used and shown to have (approximately $70 \%$ knockdown for Caveolin (Saldanha et al. 2013), approximately $40 \%$ knockdown for CK2 (Bragdon et al. 2010) and knockdown for approximately 50 \% SMAD4 (Cencetti et al. 2010)), and identical parameters were used for the current manuscript. Cells transfected or untransfected with control siRNA or dsRED were used as controls where noted. Following $4 \mathrm{~h}$, the media was exchanged to serum containing media. The next day cells were serum starved for 4 days following fixation for imaging, von Kossa or Oil Red O staining as previously described.

\section{Cell labeling for confocal microscopy imaging}

C2C12 cells were grown to $70 \%$ confluence on coverslips. Cells were transfected with plasmids encoding dsRED, BMPRIa, MCK2.1, MCK2.2 and MCK2.3. After being serum-starved for $12 \mathrm{~h}, \mathrm{C} 2 \mathrm{C} 12$ cells were stimulated or not stimulated with $40 \mathrm{nM}$ BMP2 for 1 or 3 days as indicated. Cells were washed with PBS, and fixed using ice cold methanol/acetone method as previously described (Bragdon et al. 2009) and incubated with $3 \%$ BSA for 30 min. After that, cells were labeled for $1 \mathrm{~h}$ at room temperature with PPAR $\gamma$ Mouse Monoclonal IgG (Santa Cruz Biotechnology, CA, USA) diluted 1:100 in 3\% BSA following with the diluted 1:1000 Alexa Fluor 488 donkey Anti-Mouse IgG (Invitrogen detection technologies, Eugene, Oregon, USA) for $1 \mathrm{~h}$. The nuclear stain Hoechst (Thermosceintific, West palm Beach, FL) was administered for 2 min after which the coverslips were mounted on the slides using Airvol (20 g Airvol, $80 \mathrm{ml}$ sterile water, stir mixture $60 \mathrm{C}-70 \mathrm{C} 1-2 \mathrm{~h}, 40 \mathrm{ml}$ glycerol, $0.2 \mathrm{ml}$ of $0.2 \mathrm{M}$ Tris $\mathrm{pH} 8.5$, centrifuge $18,000 \times \mathrm{g}$ ). (Nohe and Petersen 2007) PPAR $\gamma$ staining appears green in color and nuclear stain is blue. The specificity of the fluorescent secondary antibody for PPAR $\gamma$ (Alexa Fluor 488 donkey Anti-mouse $\operatorname{IgG}$ ) was also tested by labeling non-transfected cells with only the fluorescent secondary antibody (Fig. 5a control).

Quantification of membrane expression of BMPRIa, MCK2.1 MCK2.2 and MCK2.3 Cells transfected with BMPRIa, MCK2.1, MCK2.2 and MCK2.3 were grown for 1 day or 3 days after transfection. Cells were fixed using acetone/methanol and imaged using the Zeiss 780 confocal with a $63 \times$ objective. Transfected cells versus non transfected cells were counted and revealed a transfection efficiency of approximately $70 \%$. High magnification images of the membrane were collected. In order to quantify expression, gains and laser power were set in the linear range as described (Nohe and Petersen 2007).

\section{PCR}

C2C12 cells were cultured and stimulated with $40 \mathrm{nM}$ and $100 \mathrm{nM}$ of CK2.2 and CK2.3. Stimulation with HD peptide was used as a control. After 3 days, total RNA was isolated from the cells using the Trizol method in accordance with 
manufactures protocol (Invitrogen). Two-step RT- PCR was performed with the total RNA obtained, with reverse transcriptase (Qiagen). In the first step the RNA obtained was subjected to reverse transcription reaction with $1 \mu \mathrm{g}$ RNA, $2 \mu \mathrm{l}$ dNTps, $2 \mu \mathrm{l}$ oligodT, $2 \mu \mathrm{lggl}_{2}, 0.5 \mu \mathrm{l}$ RNAase inhibitor, $4 \mu \mathrm{l}$ of RNA free water and $0.75 \mu \mathrm{l}$ of Reverse Transcriptase purchased from IMPROM. In the second step, DNA obtained from the Reverse Transcription reaction was used for PCR amplification using specific primers for PRDM16 forward (F) CAGCACGGTGAAGCCATTC and PRDM16 reverse $(R)$ GCGTGCATCCGCTTGTG. PCR products were loaded on a $1 \%$ agarose gel and stained with Ethidium bromide. Actin was used as the loading control.

\section{Disruption study}

C2C12 cells were grown to $90 \%$ confluence in 24 well plates and serum starved overnight before the treatment. Cells were then transfected using Turbofect (Fermentas, Glen Burnie, MD) following manufacture's procedure. Cells were transfected with $200 \rho \mathrm{M}$ of the scrambled siRNA or siRNA against Cav1 from Santa Cruz Biotechnology (Santa Cruz, CA) as previously described (Saldanha et al. 2013). The siRNAs used were identical to those previously used shown to have approximately $70 \%$ knockdown, and identical parameters were used for the current manuscript. Non transfected cells, control siRNA or dsRED transfected cells were used as a control. Following $4 \mathrm{~h}$, the media was exchanged to serum containing media. The next day cells were serum starved for a period of 4 days, when they were fixed and either von Kossa or Oil Red O staining was performed as described.

\section{Treatment with inhibitors}

$\mathrm{C} 2 \mathrm{C} 12$ cells were grown to $90 \%$ confluence in 24 well plates and serum starved overnight before treatment. Cells were then transfected using Turbofect (Fermentas, Glen Burnie, MD) following manufacture's procedure with $3 \mu \mathrm{g}$ of DNA plasmid encoding MCK2.2. Transfected cells with MCK2.2 alone were used as positive controls. Following $4 \mathrm{~h}$, the media was exchanged to serum containing media. The next day cells were serum starved and treated with SB203580 (p38), PD98059 (MEK), or Rapamycin (mTOR) where noted. Inhibitor studies on $\mathrm{C} 2 \mathrm{C} 12$ cell were extensively described by the following experimentation (Higuchi et al. 2002; Viñals et al. 2002). After 4 days cells were fixed and stained with von Kossa stain or Oil Red O stain as described.

\section{Data analysis}

Single factor Anova, followed by Tukey Kramer post-hoc test was used to analyze all data presented. All experiments were repeated three or more times. All data was normalized to control in each experiment as noted. Outliers were removed using the Chauvenet's criterion. Error bars are represented as a standard error of the mean (SEM). Numbers and letters on the graph denote significant differences $(p<0.05)$.

\section{Results}

BMP2 mediated adipogenesis and osteogenesis is concentration dependent in $\mathrm{C} 2 \mathrm{C} 12$ cells

BMP2 is known to induce osteogenesis and adipogenesis depending on the cell type and BMP2 concentration (reviewed in (Schulz and Tseng 2009; Tseng and He 2007)). However, distinct differentiation end points resulting in adipocyte or osteoblast formation in the same cell line in order to elucidate the difference between the differentiation mechanisms is concurrently lacking.

$\mathrm{C} 2 \mathrm{C} 12$ cells were stimulated or not stimulated (control) with 40pM, $40 \mathrm{nM}$ and $200 \mathrm{nM}$ of BMP2. After 8 days, cells were fixed and stained for mineralization (von Kossa) and lipid droplets formation (Oil Red O) separately. Mineral deposits and lipid droplet formation were used as defined end points to describe osteoblastic or adipogenic phenotypes, respectively. Cells were treated equally between experiments and the results indicated that $\mathrm{C} 2 \mathrm{C} 12$ cells were able to commit to different lineages under these experimental conditions. BMP2 induced osteogenesis independent of concentration (Fig. 2a), however, only the highest concentration of BMP2 (200 nM) induced adipogenesis (Fig. 2b).

Mutation of aa213-217at BMPRIa induced adipogenesis in addition to osteogenesis

The differences observed between osteogenesis and adipogenesis shown above could be due to the activation or release of different proteins associated with the BMP receptors or the activation of downstream signaling pathways. It was reported previously that BMPRIa interacts with CK2 at three potential binding sites on BMPRIa and the addition of BMP2 leads to a release of BMPRIa from CK2. Peptides that block this interaction initiate Smad signaling independent of exogenous BMP2. Three BMPRIa mutants were created, each with a single point mutation within the CK2 binding domain (S to A) of BMPRIa. The mutants were named as the following: mutant CK2 (MCK2) at binding site 1 (MCK2.1 (aa 218S-A)), site 2 (MCK2.2 (aa 325S-A)), and site 3 (MCK2.3 (aa 214S-A)). As reported overexpression of MCK2.1, MCK2.2, and MCK2.3 in $\mathrm{C} 2 \mathrm{C} 12$ cells reveal that only MCK2.2 and MCK2.3 are able to induce osteogenesis as measured by an increase in mineralization compared to the overexpression of BMPRIa 
Fig. 2 BMP2 induces osteogenesis and at high concentration adipogenesis. $\mathrm{C} 2 \mathrm{C} 12$ cells were treated with $40 \rho \mathrm{M}$ BMP2, 40 nM BMP2, and $200 \mathrm{nM}$ BMP2 and stained for (a) mineralization using the von Kossa stain (b) or lipid droplet formation using Oil Red $\mathrm{O}$ stain. At least 4 independent experiments were performed and averages are graphed with SEM as error bars. Data was normalized to control. $\mathrm{a}=$ statistically significant different to control, $\mathrm{b}=$ statistically significant different to $40 \mathrm{pM}$ BMP2, c = statistically significant different to $40 \mathrm{nM}$ BMP2, $d=$ statistically significant different to $200 \mathrm{nM}$ BMP2
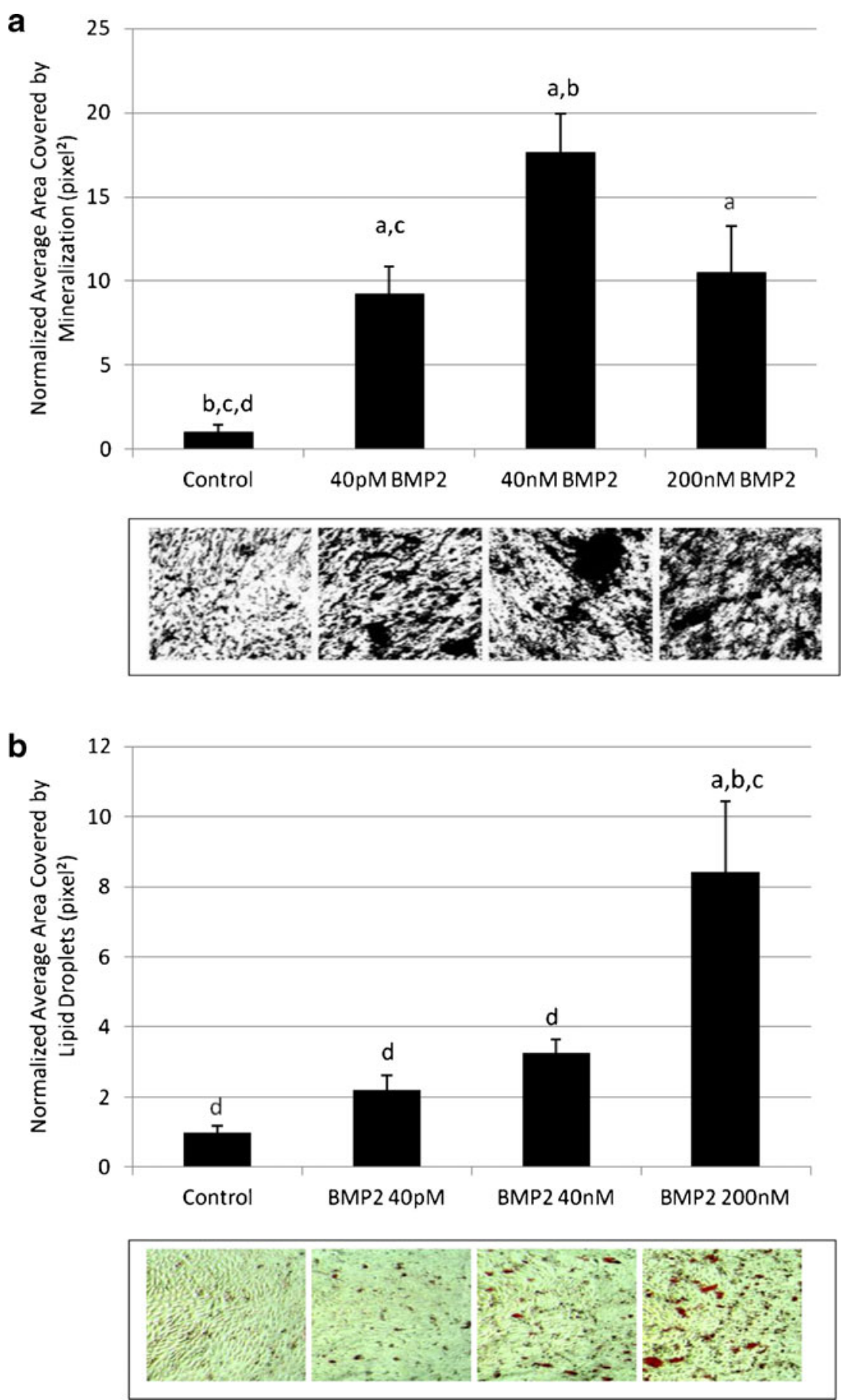

(Bragdon et al. 2009; 2011; 2010). Similar results were obtained using peptides CK2.2 and CK2.3 that release CK2 from BMPRIa (Bragdon et al. 2009; 2011; 2010). In order to determine the expression levels of BMPRIa, MCK2.1, MCK2.2 and MCK2.3 on the plasma membrane, we used quantitative confocal microscopy. For this cells were transfected with the plasmids encoding BMPRIa or the mutants and non-transfected cells served as a negative control. After 1 or 3 days cells were fixed and confocal images were obtained. Figure 3 a shows the expression of BMPRIa and the
BMPRIa mutants as indicated by the red fluorescent images since the proteins were tagged with dsRED. The nontransfected control cells showed no fluorescence therefore only the transfected cells were imaged at a high magnification to quantify the expression of BMPRIa, MCK2.1, MCK2.2 and MCK2.3 on the plasma membrane. These images were collected as far away from the nucleus as possible. As Fig. 3 shows there was no significant difference in the expression level of the three mutants and overexpression of BMPRIa. The surface quantitation experiments were verified 
Fig. 3 BMPRIa, MCK2.1, MCK2.2 and MCK2.3 expression levels. In order to test the expression of BMPRIa or the mutants on the plasma membrane, $\mathrm{C} 2 \mathrm{C} 12$ cells were transfected or not transfected (control) with plasmids encoding BMPRIa or mutant BMPRIa. After 1 and 3 days, the cells were fixed and confocal images of dsRED tagged BMPRIa or the mutants were collected. Forty high magnification images of the membrane of $\mathrm{C} 2 \mathrm{C} 12$ cells were collected for each slide and the intensity was quantified using ImageJ. a Representative images of cells at low and high magnification. b Intensities were quantified and normalized to the overexpression of BMPRIa. The intensities show no change in expression levels between day 1 and day 3. All mutants showed similar expression
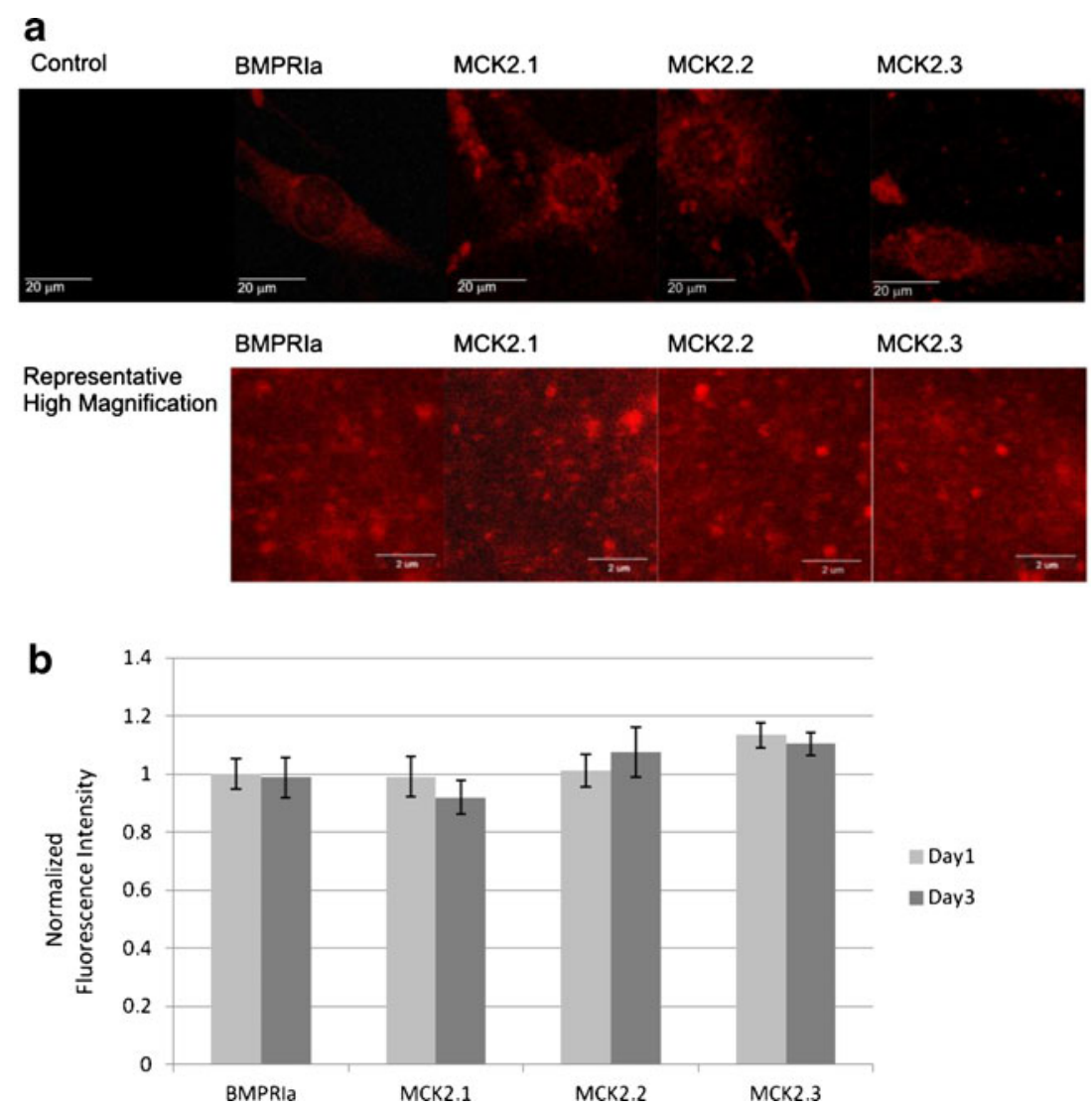

by Western blot analyses, which yielded similar results (data not shown).

The effect of the mutants on adipogenesis was then tested, cells were transfected with either the empty vector dsRED, BMPRIa, or one of the three BMPRIa mutants. As an additional control, cells were not transfected. Only MCK2.2 induced lipid droplet formation compared to the overexpression of BMPRIa, dsRED, or control cells, while MCK2.3 showed no effect (Fig. 4a). Since MCK2.1 had no significant effect compared to BMPRIa overexpression, we focused on MCK2.2 and MCK2.3. As we previously reported blocking the interaction between $\mathrm{CK} 2$ and BMPRIa at site 2 (MCK2.2) increased mineralization (Bragdon et al. 2011). Our data shown here demonstrate that MCK2.2 also increases lipid formation while inhibiting site 3 on BMPRIa (MCK2.3) increased only mineralization. This indicates that these two specific binding sites for CK2 may direct different outcomes through the BMPRIa.

To confirm the effect of the mutants, $\mathrm{C} 2 \mathrm{C} 12$ cells were stimulated with 100pM, $40 \mathrm{nM}, 100 \mathrm{nM}$, and $500 \mathrm{nM}$ of CK2.2 or CK2.3 peptides to determine their effect on adipogenesis (Fig. 4b). The HD peptide (control peptide) and non-stimulated cells were used as controls for each concentration. Eight days after stimulation with the peptides, lipid droplet formation was determined with Oil Red $\mathrm{O}$ stain. Lower concentrations (100pM and $40 \mathrm{nM})$ of CK2.2 induced adipogenesis (Fig. 4b). This confirms the result of the mutant of $\mathrm{MCK} 2.2$ on adipogenesis. Interestingly $\mathrm{CK} 2.3$ stimulation at a high concentration seemed to inhibit adipogenesis in $\mathrm{C} 2 \mathrm{C} 12$ cells, this maybe due to a role independent of BMPRIa, since this is not observed by overexpressing MCK2.3

PPAR $\gamma$ is activated when CK2 interaction site 2 on BMPRIa is blocked

PPAR $\gamma$ expressed in adipose tissues is induced during differentiation and is translocated to the nucleus before transcriptional activation of most adipose specific genes (Kubota et al. 1999). In order to confirm adipogenesis due to the mutant MCK2.2 and the lack of adipogenesis with MCK2.3, cells were transfected with the empty vector dsRED, BMPRIa, MCK2.2, or MCK2.3 and fluorescently stained for PPAR $\gamma$. Nuclear translocation was visualized by co-staining with the nuclear Hoechst stain. As can be seen from Fig. 5a, PPAR $\gamma$ nuclear localization is only seen with the cells transfected with MCK2.2. PPAR $\gamma$ was not localized to the nucleus with the overexpression of dsRED, BMPRIa, or MCK2.3.

Loss of interaction between CK2 and BMPRIa at the phosphorylation site 2 promotes brown Fat formation

To investigate the nature of fat formation, we used PRDM16 which has been shown to be up regulated in 

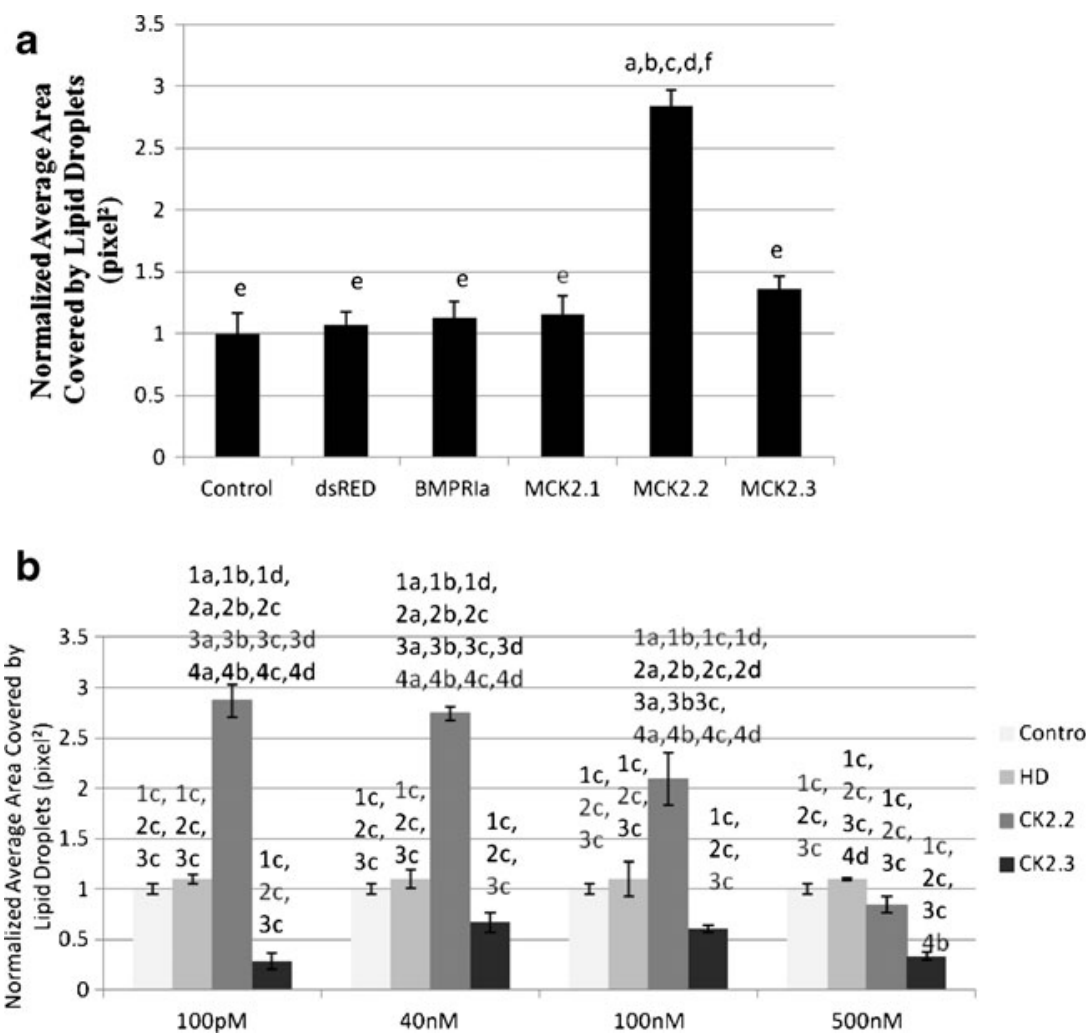

Fig. 4 Blockage of CK2.2-BMPRIa interaction induces adipogenesis. a Mutants for each of the CK2 binding sites of BMPRIa, BMPRIa, or dsRED were transfected in $\mathrm{C} 2 \mathrm{C} 12$ cells and stained for lipid droplet formation using Oil Red O stain. Controls were non-transfected cells. MCK2.2 induced adipogenesis compared to BMPRIa overexpression and controls. At least 4 independent experiments were performed and averages are graphed with SEM as error bars. Data was normalized to the control. $\mathrm{a}=$ statistically significant different to control, $\mathrm{b}=$ statistically significant different to dsRED, $\mathrm{c}=$ statistically significant different to BMPRIa, $\mathrm{d}=$ statistically significant different to MCK2.1, e = statistically significant different to MCK $2.2, \mathrm{f}=$ statistically significant

brown adipose tissue (BAT) as compared to white adipose tissue (WAT) and is used as a marker of BAT (Seale et al. 2007). Although recent studies show that PRDM16 expression is evident in subcutaneous WAT in mice, still PRDM16 is used in this study as a marker for BAT. This is due to the fact that have shown that PRDM16 is a marker for BAT formation in $\mathrm{C} 2 \mathrm{C} 12$ cells as well as in primary myogenic cells (Seale et al. 2008). However, we cannot rule out that WAT formation is also influenced.

Brown adipocytes mainly oxidize fuels and dissipate energy in the form of heat. Brown fat pre-adipocytes depleted of PRDM16 differentiated into myocytes (Seale et al. 2007). In the present study $\mathrm{C} 2 \mathrm{C} 12$ cells were stimulated with the HD (control peptide), CK2.2, and CK2.3 peptides for a period of $72 \mathrm{~h}$ and RNA was extracted. cDNA was then obtained by RT-PCR and the expression of PRDM16 was tested by PCR. GAPDH was used as a loading control. HD peptide different to MCK2.3. b. C2C12 cells were treated with $100 \rho \mathrm{M}$, $40 \mathrm{nM}$, and $500 \mathrm{nM}$ of designed peptides and stained for lipid droplet formation using Oil Red O stain. CK2.2 induced adipogenesis at $100 \mathrm{\rho M}, 40 \mathrm{nM}$ and $100 \mathrm{nM}$. At least 4 independent experiments were performed and averages are graphed with SEM as error bars. Data was normalized to the control at each concentration. $a=$ statistically significant different to control, $b=$ statistically significant different to $\mathrm{HD}, \mathrm{c}=$ statistically significant different to CK2.2, $\mathrm{d}=$ statistically significant different to CK2.3, 1,2,3,4 = statistically significant different within $100 \mathrm{pM}, 40 \mathrm{nM}, 100 \mathrm{n}$ and $500 \mathrm{nM}$ respectively

stimulation acts as a negative control. As has been shown before (Bragdon et al. 2010) C2C12 cells stimulated with the CK2.3 peptides have shown significant osteogenesis as opposed to those stimulated with the control HD peptide. The DNA gel showed the presence of PRDM16 with the treatment of peptide CK2.2, suggesting that there is differentiation of BAT from C2C12 cells (Fig. $5 b$ ).

Noggin treatment inhibits BMP2-induced mineralization and lipid droplet formation but not CK2.2 or CK2.3

In order to determine if the effect of the peptides is due to an upregulation of BMP2, we used Noggin $(40 \mathrm{nM})$ to block BMP2 interaction with BMPRIa. Non-stimulated cells were used as controls. As Fig. 6 indicates, while Noggin inhibits mineralization and adipogenesis mediated by BMP2, it had no effect on mineralization or adipogenesis mediated by the peptides. Taken together 
Fig. 5 Loss of interaction between CK2 and BMPRIa at the aa324328 leads to nuclear localization of PPAR $\gamma$ and upregulation of BAT marker PRDM16. a $\mathrm{C} 2 \mathrm{C} 12$ cells were transfected with BMPRIa, MCK2.2, and MCK2.3 for 3 days and stained with PPAR $\gamma$ antibody and Hoechst nuclear stain. Minimal nuclear translocation of PPAR $\gamma$ is observed upon transfection with BMPRIa, but when cells were transfected with MCK2.2, all PPAR $\gamma$ is activated and localized to nucleus. As control cells were transected with a plasmid expressing monomeric dsRED and labeled for PPAR gamma. As an additional control cells were only labeled with the secondary Alexa488 antibody without primary antibody (control). All cell nuclei were stained using the Hoechst stain. b To determine whether differentiated adipocytes express PRDM16, a marker of BAT, C2C12 cells were cultured and stimulated with CK2.2 or CK2.3 peptides at $40 \mathrm{nM}$ and $100 \mathrm{nM}$. Cells stimulated with HD peptide were used as a control. Interestingly no PRDM16 was detected in the control group, although the red oil stain showed some few adipocytes in the well. This may be due to the low amount of the adipocytes present in the control. Total RNA was isolated from cells after 3 days and RT-PCR was performed followed by PCR. Only samples stimulated with CK 2.2 showed clear expression of PRDM16. GAPDH is used as a control

these data with data previously published, which show that siRNA against BMPRIa abolishes CK2.3 mediated Smad signaling suggests that the peptides act downstream of BMP2 and BMPRIa (Bragdon et al. 2011).

MCK2.2 induced osteogenesis is dependent on the expression of Cav1, CK2, and Smad4 but not MCK2.3 mediated osteogenesis

In order to identify a possible signaling mechanism involved in the differentiation of osteogenesis induced by blocking the interaction between CK2 and BMPRIa, key proteins belonging to canonical BMP2 signaling was downregulated using siRNA. BMP receptors localize in distinct membrane domains such as caveolae and clathrin coated pits. Caveolae are composed of Cav1 and downregulation of Cav1 inhibits caveolae formation on the plasma membrane. Previous studies showed that downregulation of $\mathrm{CK} 2$ in $\mathrm{C} 2 \mathrm{C} 12$ cells activated $\mathrm{Smad}$ signaling and it was shown this effect is due to the inhibition of the interaction of CK2 with BMPRIa (Bragdon et al. 2010). Although the BMP receptors interact with CK2 and the mutants and peptides interfere with the CK2-BMPRIa interaction, it is not clear whether CK2 is necessary for signaling downstream of BMPRIa. Therefore, $\mathrm{C} 2 \mathrm{C} 12$ cells were transfected with $3 \mu \mathrm{g}$ MCK2.2, MCK2.3 and 20 pmoles of siRNA against CK2, Cav1, Smad4, or control (scrambled siRNA) where noted. Additional controls consisted of non-transfected cells and cells transfected with only the control siRNA. Cells transfected with scrambled siRNA did not have an effect. Transfected cells with MCK2.2 or MCK2.3 alone were used as positive controls, due to their ability to induce osteogenesis. After 4 days cells were fixed and stained for mineralization using von Kossa. Downregulation of CK2, Cav1, and Smad4

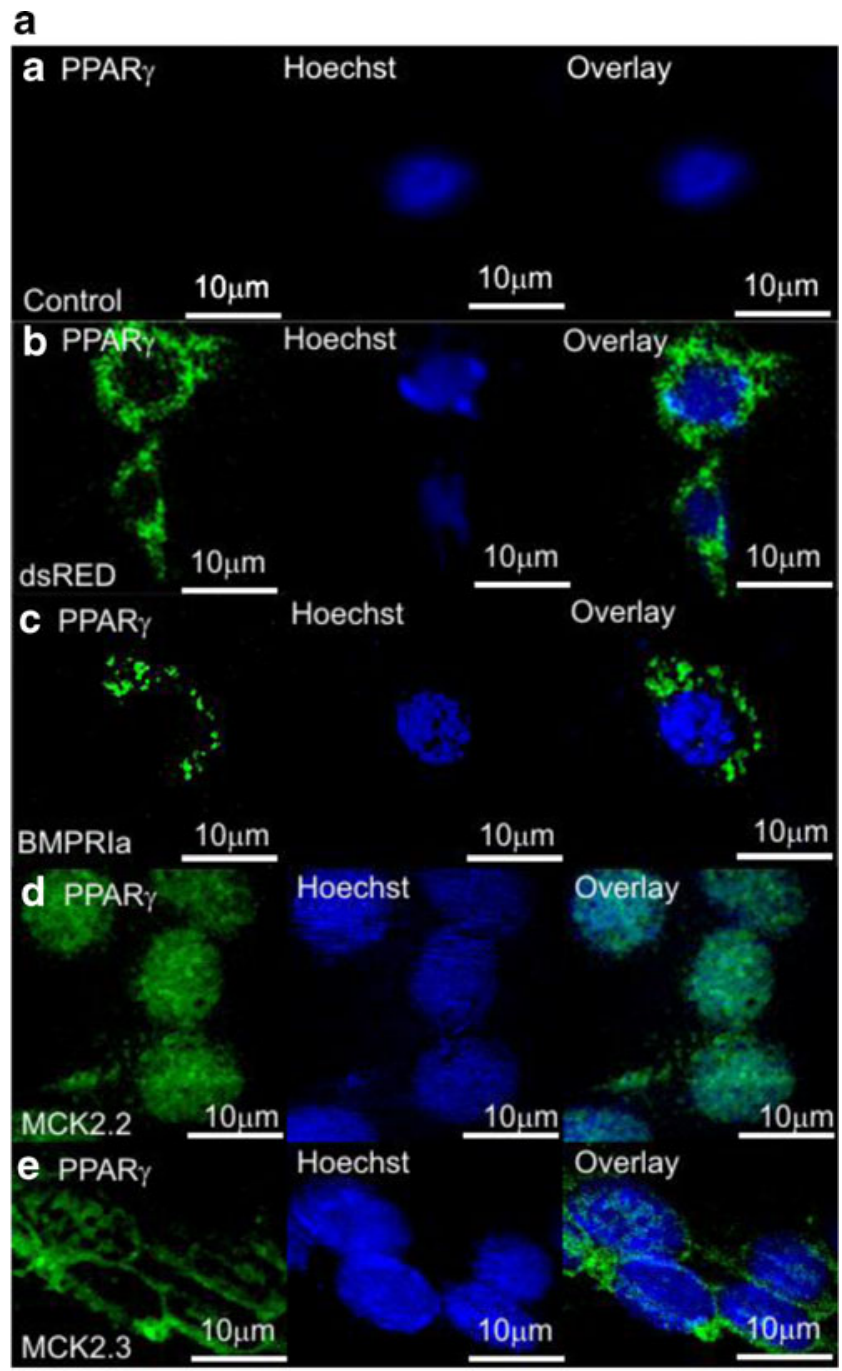

b

\begin{tabular}{|l|c|c|c|c|c|}
\hline \hline & HD & CK2.2 & CK2.2 & CK2.3 & CK2.3 \\
& & $40 \mathrm{nM}$ & $\begin{array}{c}100 \mathrm{nM} \\
40 \mathrm{nM}\end{array}$ & $100 \mathrm{nM}$ \\
\hline PRDM16 & & & & & \\
& & & & & \\
\hline GAPDH & & & & & \\
& & & & & \\
\hline
\end{tabular}

showed approximately a significant $60 \%$ decrease in mineralization for MCK2.2, (Fig. 7a-b).

Presence of CK2, Cav1, and Smad4 are needed for MCK2.2 induced adipogenesis

Since the overexpression of MCK2.2 also induced adipogenesis in $\mathrm{C} 2 \mathrm{C} 12$ cells, the role of $\mathrm{CK} 2$, Cav1, and Smad4 were investigated. Cells were transfected with plasmids encoding MCK2.2 and 20 pmoles of siRNA against CK2, Cav1, Smad4 or control (scrambled siRNA) where noted. Cells transfected with scrambled siRNA did not show an effect Overexpression of MCK2.2 alone was used as positive control due to its ability to induce adipogenesis. 
a

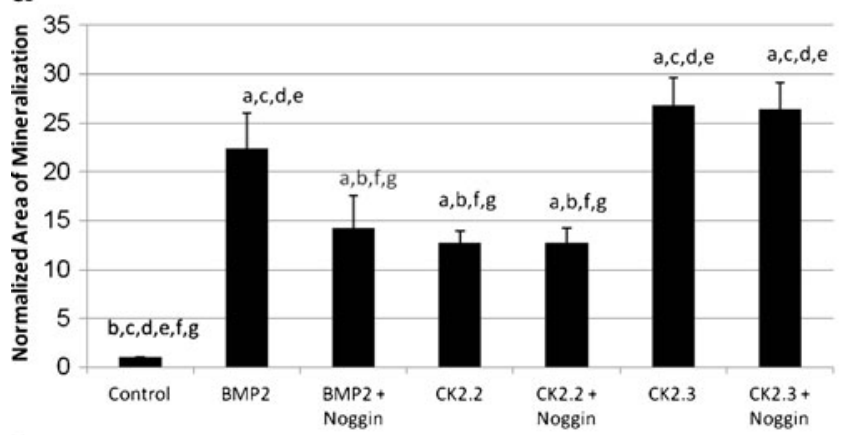

b

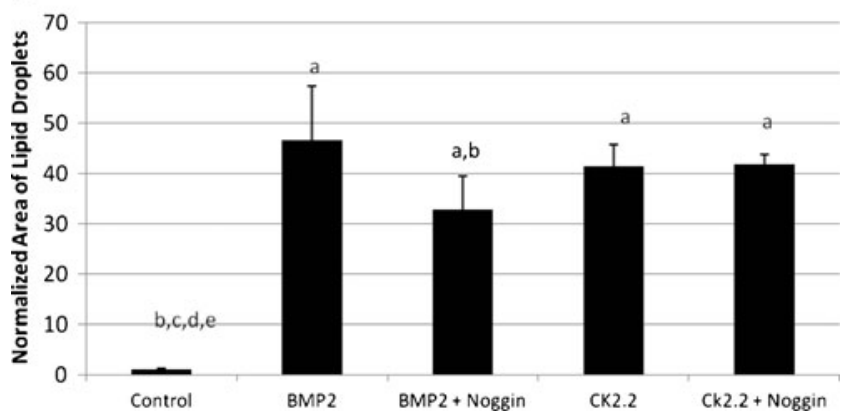

Fig. 6 Addition of Noggin to BMP2 but not to CK2.2 or CK2.3 stimulation inhibits mineralization. $\mathrm{C} 2 \mathrm{C} 12$ cells were treated with $40 \mathrm{nM}$ BMP2, $100 \mathrm{nM}$ CK2.2, or CK2.3 peptides. Noggin $(40 \mathrm{nM})$ was added where noted. Non-stimulated C2C12 cells were used as controls. After 5 days mineralization (A) or lipid formation (B) was measured using Von Kossa or Oil Red O staining respectively. a Addition of Noggin to BMP2 inhibited mineralization, while addition of Noggin to peptides did not result in a decrease of mineralization. b Noggin treatment significantly decreased lipid droplet formation for only BMP2 stimulation. Significance $(p<0.05)$ is denoted by a $=$ statistically significant different to control, $b=$ statistically significant different to BMP2, $\mathrm{c}=$ statistically significant different to BMP2 + Noggin, $\mathrm{d}=$ statistically significant different to CK2.2, e = statistically significant different to CK2.2 + Noggin, f statistically significant different to CK2.3, g = statistically significant different to CK2.3 + Noggin

After 4 days cells were fixed and stained for lipid droplet formation using Oil Red O. Downregulation of CK2, Cav1, and Smad4 by siRNA significantly decreased cell differentiation into adipocytes in MCK2.2 transfected cells as shown by the reduced number of lipid droplets (Fig. 7c).

mTor AKT pathway regulates osteoblastic differentiation while p38 and MEK pathway regulates adipocyte differentiation

BMP2 signal transduction downstream of its receptors utilizes Smad1, 5, and 8, PI3K/AKT/mTOR, ERK/MEK, JNK, p38, and NF- $\mathrm{KB}$ to regulate osteogenesis (Fig. 1b) summarized in (Bragdon et al. 2011), while the Smad and p38 pathways can also lead to adipocyte differentiation (Fig. 1c) (Hata et al. 2003). Several possibilities could explain why signaling pathways activate the same intermediates but result in two different

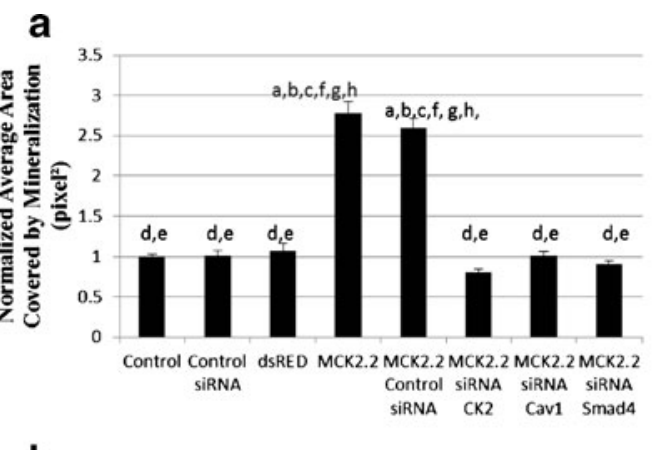

b
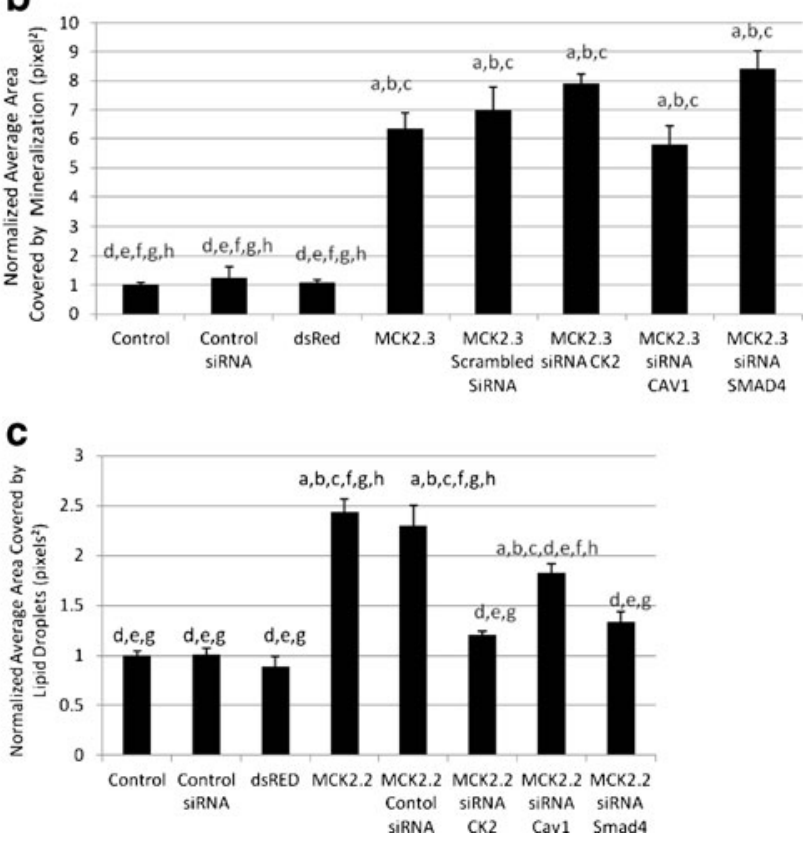

Fig. 7 Downregulation using siRNAs demonstrated that CK2, Cav1 and Smad4 are important for osteogenesis and adipogenesis for MCK2.2, but not for MCK2.3. C2C12 cells were transfected with $3 \mu \mathrm{g}$ MCK2.2 (a and c) or MCK2.3 (b) and $20 \rho \mathrm{M}$ of siRNA against CK2, Cav1 or Smad4, or control siRNA where noted. Control cells were either not transfected or transfected with only the control siRNA. Cells were stained for ( $\mathbf{a}$ and b) mineralization using von Kossa staining or (c) lipid droplet formation using Oil Red $\mathrm{O}$ staining. At least 4 independent experiments were performed and averages are graphed with SEM as error bars. Data was normalized to controls. (a.,c) a = statistically significant different to control, b = statistically significant different to control siRNA, $\mathrm{c}=$ statistically significant different to dsRED, $\mathrm{d}=$ statistically significant different to MCK2.2, $\mathrm{e}=$ statistically significant different to MCK2.2 + siRNA, $\mathrm{f}=$ statistically significant different to MCK2.2 + SiRNA CK2, g = statistically significant different to MCK2.2 + siRNA Cav1,h statistically significant different to MCK2.2 + siRNA Smad4.(b) a = statistically significant different to control, $\mathrm{b}=$ statistically significant different to control siRNA, $\mathrm{c}=$ statistically significant different to dsRED, $\mathrm{d}=$ statistically significant different to MCK2.3, e = statistically significant different to MCK2.3 + siRNA, $\mathrm{f}=$ statistically significant different to MCK2.3 + SiRNA CK2, $g$ = statistically significant different to MCK2.3 + siRNA Cav1, h statistically significant different to MCK2.3 + siRNA Smad4

outcomes. To address the possibility that BMPRIa-CK2 mediated adipocyte differentiation is initiated by signaling via a different pathway(s) compared to osteoblast differentiation, 
inhibitors were used to disrupt specific signaling pathways and the effect on cell differentiation was observed.

$\mathrm{C} 2 \mathrm{C} 12$ cells were transfected with MCK2.2 plasmids to induce adipogenesis and osteogenesis. As controls cells were non-transfected or transfected with dsRED. The following day the cells were treated with either $1 \mu \mathrm{M}$ SB203580 (p38), $5 \mu \mathrm{M}$ PD98059 (MEK), or $300 \mathrm{nM}$ Rapamycin (mTOR) where noted (Fig. 8). After 4 days cells were fixed and stained with von Kossa stain (mineralization) or Oil Red O stain (lipid droplet). In cells transfected with MCK2.2 plasmid, Rapamycin significantly inhibited osteogenesis, but MEK and p38 inhibitors had no effect on mineralization (Fig. 8a). When the same treatment was used for $\mathrm{C} 2 \mathrm{C} 12$ cells to study MCK2.2 induced adipogenesis, it was observed that p38 and MEK inhibitors significantly reduced lipid droplet formation, but Rapamycin had no significant effect (Fig. 8b). This observation indicates that mTor-AKT pathway is important for osteoblastic differentiation while p38 and MEK signaling are important for adipogenesis in cells utilizing the CK2.2 signaling pathway.

Osteoblastic differentiation induced by MCK2.3 is mediated through ERK-MEK pathway

To study the differentiation pathway of MCK2.3 induced osteogenesis, specific inhibitors were used and the effect on mineralization was analyzed. $\mathrm{C} 2 \mathrm{C} 12$ cells were transfected to overexpress MCK2.3 to induce osteogenesis and the next day the cells were treated with either $1 \mu \mathrm{M} \mathrm{SB} 203580$ (p38), $5 \mu \mathrm{M}$ PD98059 (MEK), and $300 \mathrm{nM}$ Rapamycin (mTOR). After 4 days cells were fixed and von Kossa stain was used to assess mineralization. The average area covered by mineralization/cell was measured since the number of cells per well was not uniform. Analysis with Image $\mathbf{J}$ showed that the MEK inhibitor significantly decreased osteogenesis while inhibitors for p38 and mTOR had no effect (Fig. 8c).

Taken together these results show that the BMPRIa mutant, MCK2.2, induced osteoblast and adipocyte differentiation and the outcome required different functional pathways in the C2C12 cell line, namely, osteogenesis needs the Smad and mTor-AKT pathway, while adipogenesis was dependent on Smad, p38, and MEK pathways (Fig. 9). Further MCK2.3 only induced osteoblast differentiation which needed functioning MEK. Inhibitor studies on $\mathrm{C} 2 \mathrm{C} 12$ cell were extensively studied to support the following experimentation (Higuchi et al. 2002; Viñals et al. 2002).

\section{Discussion}

Osteoblasts and adipocytes are derived from the MSC lineage and the mechanism regulating the differentiation between these two lineages is poorly understood. One of the
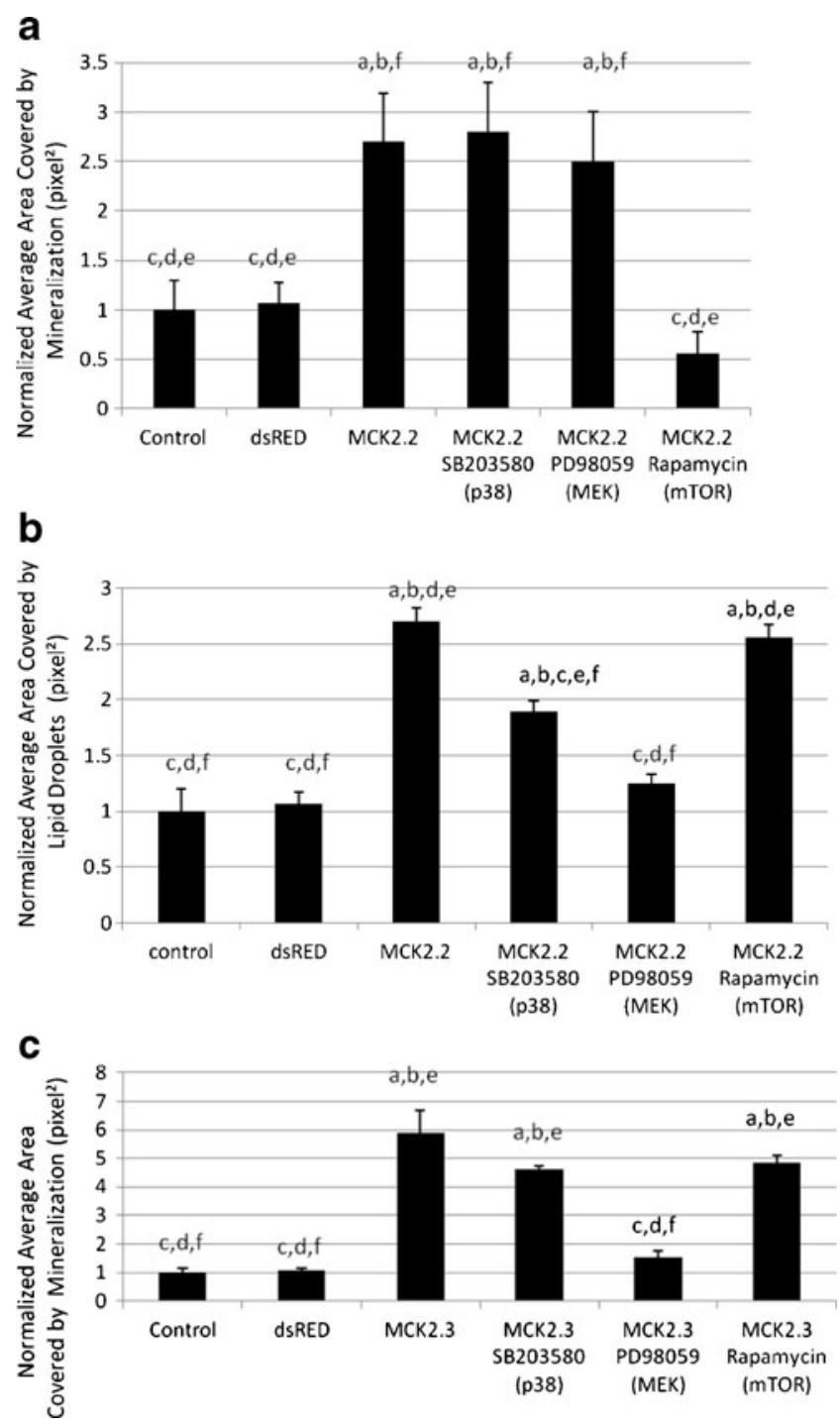

Fig. 8 Osteoblastic differentiation occurs through mTor-AKT pathway, and adipocyte differentiation occurs through p38, and MEK pathway for MCK2.2. Osteoblastic differentiation occurs via MEK pathway for MCK2.3. C2C12 cells were transfected with MCK2.2 or MCK2.3 and treated with $1 \mu \mathrm{M}$ SB203580 (p38), $5 \mu \mathrm{M}$ PD98059 (MEK), $300 \mathrm{nM}$ Rapamycin (mTOR) inhibitors where noted. Transfected cells with MCK2.2, MCK2.3, or dsRED and nontransfected cells were used as controls. Cells were stained for (a and c) mineralization using von Kossa staining or (b) lipid droplet formation using Oil Red O staining. At least 4 independent experiments were performed and averages are graphed with SEM as error bars. a = statistically significant different to control, $b=$ statistically significant different to dsRED, $\mathrm{c}=$ statistically significant different to MCK2.3 orMCK2.2, $\mathrm{d}=$ statistically significant different to MCK2.3 or MCK2.2 + SB203580, e = statistically significant different to MCK2.3 or MCK2.2 + PD98059, f = statistically significant different to MCK2.3or MCK2.2 + Rapamycin

key growth factors influencing MSC differentiation is BMP2. While BMP2 has been approved by the FDA for spinal fusions, and is demonstrating promising results for reversing the osteoporotic phenotype in mice (Marcus et al. 2008), it also leads to adipocyte differentiation upon 
Fig. 9 New proposed model of BMP2-induced C2C12 cells differentiation. Release of CK2 from different CK2-BMPRIa interaction sited regulates differentiation into osteoblasts (release from CK2.2, aa 324328) via activation of Smad4 and mTor signaling pathways or via ERK/MEK signaling pathway (release from CK2.3, aa 213-217), and adipocytes (release from CK2.2, aa 324328) by activation of Smad4, p38, and MEK signaling pathways

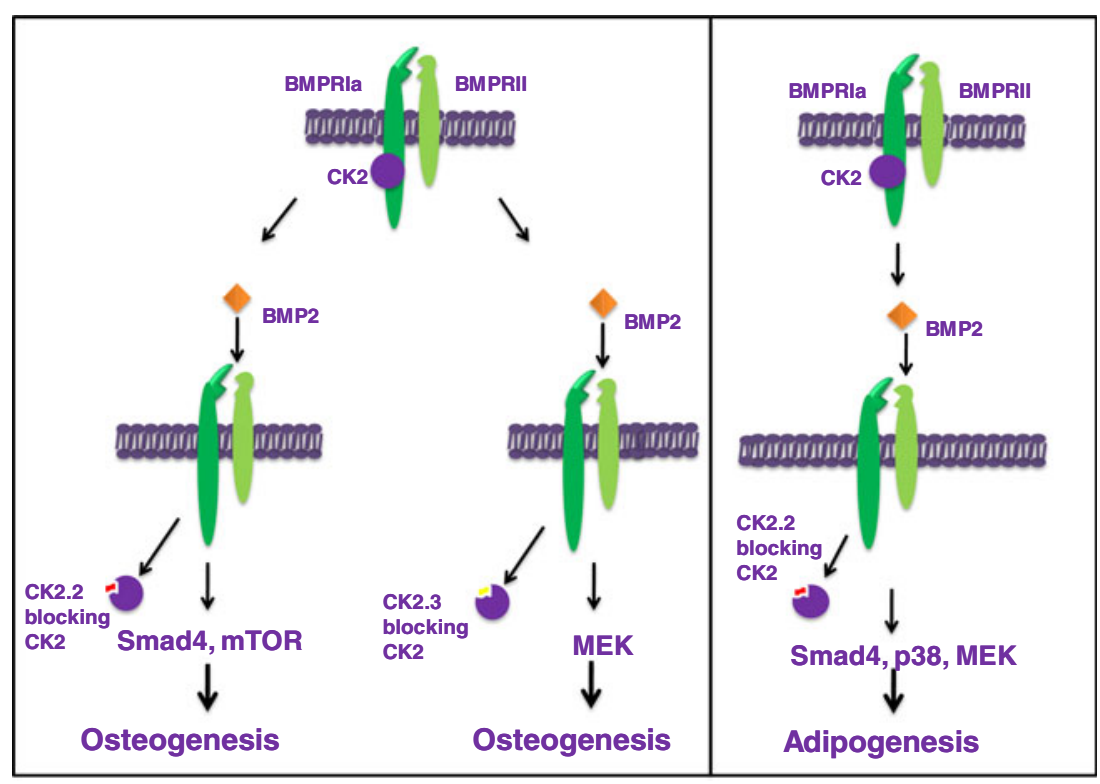

treatment. $\mathrm{C} 2 \mathrm{C} 12$ cells also have the potential to differentiate into myocytes. This process however takes approximately 3-4 weeks in normal media under serum starvation (Griffin et al. 2004). In this paper we focus on the earlier time points. The actual ratio of differentiated osteoblasts to adipocytes upon stimulation has not been looked at, and the mechanism of differentiation is unclear. There are some speculations as to why the same ligand binding results in two distinct outcomes, but no clear and agreed upon answer has been found to date.

BMP2 signaling cascade begins when BMP2 binds to heteromeric receptor complexes consisting of at least one type I and one type II receptor. Upon binding of BMP2, the type II receptor phosphorylates and activates the type I receptor at the GS-box. The serine/threonine kinase type I receptor then activates downstream signaling (Derynck and Feng 1997; Itoh et al. 2000; Massague 1998), inducing Smaddependent, and Smad-independent signaling pathways (Hartung et al. 2006; Hassel et al. 2003). Smad-independent signaling pathways include, p38, JNK, ERK, PI3K, and NFkB (Bragdon et al. 2010; Sieber et al. 2009) (Fig. 1). The mechanism for the activation of different downstream effectors is not fully understood.

A Prosite search revealed three sites at which the CK2 alpha subunit could phosphorylate BMPRIa at amino acids 213-217 (SLKD), 324-328, (SLYD) and 475-479 (SYED). Peptides were designed with the Antennapedia homeodomain signal sequence for cellular uptake and incorporated one of these binding sites, CK2.1 (SYED), CK2.2 (SLYD), and CK2.3 (SLKD). Loss of interaction between CK2 and a specific site on the BMPRIa led to differentiation into osteoblasts and adipocytes depending on the specific interaction site and concentration (Figs. 2, 3, 4 and 5). Similar results were obtained by overexpression of mutants lacking the CK2 phosphorylation sites. This is contrary to recent studies. In these studies CK2 interacts with Alk1 and this interaction is necessary to activate signaling. Additionally, CK2 enhanced Smad1, 5 and 8 signaling in response to BDNF and BMP7 (Chaverneff and Barrett 2009). Therefore CK2 signaling mechanisms depend on the types of ligands as well as different BMP receptors. As we recently demonstrated the peptides CK2.1, CK2.2 and CK2.3 effect BMP signaling pathways downstream of BMPRIa (Bragdon et al. 2011). Similarly as shown in this paper the mutants seem to induce BMP2 signaling independent of BMP2 present. However whether the pathways activated are similar still needs to be addressed.

This study demonstrates that pathways that possibly fine tune osteogenesis and adipogenesis are associated to different CK2 sites on BMPRIa. MCK2.2 mediated osteogenesis was dependent on functional Smad and mTor-AKT pathways while the MCK2.3-induced osteogensis required functional MEK signaling. Only MCK2.2 induced lipid droplet formation and it was dependent of the Smad, p38 and MEK pathways.

BMP2 induces osteoblast differentiation in $\mathrm{C} 2 \mathrm{C} 12$ cells and the MEK/ERK pathway is involved, specifically BMP2 initiates the phosphorylation of ERK during osteogenesis. BMP2-induced osteoblast differentiation markers, alkaline phosphatase (ALP) staining, Osterix, and the expression of collagen type I $\alpha$ and ALP are decreased with the incubation with the MEK inhibitor, U0126, in C2C12 cells. Additionally BMP2 activated ERK increases mRNA and protein levels of RUNX2 and its stability suggesting a possible mechanism (Gallea et al. 2001; Jun et al. 2010). The MEK inhibitor, PD98059, decreases osteocalcin (a marker for osteoblasts) expression in $\mathrm{C} 2 \mathrm{C} 12$ cells although its direct effect on ALP is unclear (Gallea et al. 2001). 
Although the direct activation of the MEK/ERK pathway due to MCK2.2 or MCK2.3 was not shown here, the previous studies did demonstrate that BMP2 activates the MEK/ERK pathway in $\mathrm{C} 2 \mathrm{C} 12$ cells and the pathway directs osteogenesis (Gallea et al. 2001; Jun et al. 2010), supporting the results with the MEK inhibitor and MCK2.3. It does not explain the results demonstrating MEK/ERK pathway is involved with adipogenesis via MCK2.2, although in primary bone marrow stromal stem cells ERK activation is needed for adipogenesis (Liao et al. 2008). These results indicate further research is needed to elucidate the complexity involved with the regulation of the BMP2 signaling mechanism at the receptor level.

The signaling pathways, p38 and Smad are important for osteogenesis and adipogenesis (Hata et al. 2003; Noth et al. 2003). Differentiation into adipocytes and osteoblasts seems to be dependent on cell type. In C3H10T1/2 cells both p38 and Smad were shown to be required for differentiation into adipocytes by inducing and upregulating PPAR $\gamma$ (Hata et al. 2003). In trabecular bone-derived osteoblasts, the Smad pathway was shown to be important for induction of osteoblast maturation (Noth et al. 2003). Both studies were done on cells that were further along in the differentiation pathway and do not fully answer the question of initiation of differentiation of MSCs. Additionally, while PI3K was shown to be activated by BMP2 stimulation (Bragdon et al. 2010; Sugimori et al. 2005), no solid evidence was presented for the mTor-AKT pathway in the osteogenesis in $\mathrm{C} 2 \mathrm{C} 12$ cell differentiation. The results shown here suggest that mTor-AKT pathway is important for MCK2.3 induced $\mathrm{C} 2 \mathrm{C} 12$ cell differentiation into osteoblasts.

A limitation of this study is the methods used to study the end points for osteogenesis and adipogenesis, von Kossa (mineralization) and Oil Red O (lipid formation). Both methods are semi-quantitative and relative with the image process used. Other studies have shown BMP2-induced osteoblast differentiation in $\mathrm{C} 2 \mathrm{C} 12$ cells using various (Gallea et al. 2001; Jun et al. 2010) methods including von Kossa and ALP (Bragdon et al. 2010). It was shown that ppary translocates to the nucleus and Prdm16 expression is present with the overexpression of MCK2.2, which both supports adipogenesis.

This study showed that $\mathrm{C} 2 \mathrm{C} 12$ cells utilize both Smaddependent and Smad- independent signaling pathways for MCK2.2 mediated osteogenesis and adipogenesis, but only the Smad- independent pathway, MEK/ERK for MCK2.3 mediated osteogenesis. Key differences in the cell differentiation pathway leading to osteoblast and adipocyte differentiation induced by the BMPRIa-CK2 interaction were identified. It also opened a new chapter for research related to BMP receptor regulation of BMP2-dependent stem cell signaling and differentiation, and raised questions that will hopefully be answered in the near future. Also the finding that CK2.3 reduces adipogenesis at high concentrations may indicate that the peptide CK2.3 has additional functions within the cell independent of its regulation of blocking CK2.3 downstream of BMPRIa.

\section{References}

Bragdon B, Thinakaran S, Bonor J, Underhill TM, Petersen NO, Nohe A (2009) FRET reveals novel protein-receptor interaction of bone morphogenetic proteins receptors and adaptor protein 2 at the cell surface. Biophys J 97:1428-1435

Bragdon B, Thinakaran S, Moseychuk O, King D, Young K, Litchfield DW, Petersen NO, Nohe A (2010) Casein kinase 2 beta-subunit is a regulator of bone morphogenetic protein 2 signaling. Biophys $\mathrm{J}$ 99:897-904

Bragdon B, Thinakaran S, Moseychuk O, Gurski L, Bonor J, Price C, Wang L, Beamer WG, Nohe A (2011) Casein kinase 2 regulates in vivo bone formation through its interaction with bone morphogenetic protein receptor type Ia. Bone 49(5):944 954

Bragdon B, Moseychuk O, Saldanha S, King D, Julian J, Nohe A (2012) Bone morphogenetic proteins: a critical review. Cell Signal 23:609-620

Cencetti F, Bernacchioni C, Nincheri P, Donati C, Bruni P (2010) Transforming growth factor- $\hat{I}^{2} 1$ induces transdifferentiation of myoblasts into myofibroblasts via up-regulation of sphingosine kinase-1/S1P3 axis. Mol Biol Cell 21:1111-1124

Chaverneff F, Barrett J (2009) Casein kinase II contributes to the synergistic effects of BMP7 and BDNF on Smad 1/5/8 phosphorylation in septal neurons under hypoglycemic stress. J Neurochem 109:733-743

Chen D, Zhao M, Mundy GR (2004) Bone morphogenetic proteins. Growth Factors 22:233-241

Derynck R, Feng XH (1997) TGF-beta receptor signaling. Biochim Biophys Acta 1333:F105-F150

Duncan JS, Litchfield DW (2008) Too much of a good thing: the role of protein kinase $\mathrm{CK} 2$ in tumorigenesis and prospects for therapeutic inhibition of CK2. Biochim Biophys Acta 1784:33-47

Gallea S, Lallemand F, Atfi A, Rawadi G, Ramez V, Spinella-Jaegle S, Kawai S, Faucheu C, Huet L, Baron R, Roman-Roman S (2001) Activation of mitogen-activated protein kinase cascades is involved in regulation of bone morphogenetic protein-2-induced osteoblast differentiation in pluripotent $\mathrm{C} 2 \mathrm{C} 12$ cells. Bone 28:491-498

Gilboa L, Nohe A, Geissendorfer T, Sebald W, Henis YI, Knaus P (2000) Bone morphogenetic protein receptor complexes on the surface of live cells: a new oligomerization mode for serine/ threonine kinase receptors. Mol Biol Cell 11:1023-1035

Griffin MA, Sen S, Sweeney HL, Discher DE (2004) Adhesioncontractile balance in myocyte differentiation. J Cell Sci 117:5855-5863

Guicheux J, Lemonnier J, Ghayor C, Suzuki A, Palmer G, Caverzasio J (2003) Activation of p38 mitogen-activated protein kinase and cJun-NH2-terminal kinase by BMP-2 and their implication in the stimulation of osteoblastic cell differentiation. J Bone Miner Res 18:2060-2068

Hartung A, Bitton-Worms K, Rechtman MM, Wenzel V, Boergermann JH, Hassel S, Henis YI, Knaus P (2006) Different routes of bone morphogenic protein (BMP) receptor endocytosis influence BMP signaling. Mol Cell Biol 26:7791-7805 
Hassel S, Schmitt S, Hartung A, Roth M, Nohe A, Petersen N, Ehrlich M, Henis YI, Sebald W, Knaus P (2003) Initiation of Smaddependent and Smad-independent signaling via distinct BMPreceptor complexes. J Bone Joint Surg Am 85-A(Suppl 3):44-51

Hata K, Nishimura R, Ikeda F, Yamashita K, Matsubara T, Nokubi T, Yoneda T (2003) Differential roles of Smad1 and p38 kinase in regulation of peroxisome proliferator-activating receptor gamma during bone morphogenetic protein 2-induced adipogenesis. Mol Biol Cell 14:545-555

Higuchi C, Myoui A, Hashimoto N, Kuriyama K, Yoshioka K, Yoshikawa H, Itoh K (2002) Continuous inhibition of MAPK signaling promotes the early osteoblastic differentiation and mineralization of the extracellular matrix. J Bone Miner Res 17:17851794

Itoh S, Itoh F, Goumans MJ, Ten Dijke P (2000) Signaling of transforming growth factor-beta family members through Smad proteins. Eur J Biochem 267:6954-6967

Jun JH, Yoon W-J, Seo S-B, Woo K-M, Kim G-S, Ryoo H-M, Baek JH (2010) BMP2-activated Erk/MAP kinase stabilizes Runx2 by increasing p300 levels and histone acetyltransferase activity. J Biol Chem 285:36410-36419

Kawai M, Hattori H, Yasue K, Mizutani H, Ueda M, Kaneda T, Hoshino T (1994) Development of hemopoietic bone marrow within the ectopic bone induced by bone morphogenetic protein. Blood Cells 20:191-199, discussion 200-1

Kimura N, Matsuo R, Shibuya H, Nakashima K, Taga T (2000) BMP2induced apoptosis is mediated by activation of the TAK1-p38 kinase pathway that is negatively regulated by Smad6. J Biol Chem 275:17647-17652

Kubota N, Terauchi Y, Miki H, Tamemoto H, Yamauchi T, Komeda K, Satoh S, Nakano R, Ishii C, Sugiyama T, Eto K, Tsubamoto Y, Okuno A, Murakami K, Sekihara H, Hasegawa G, Naito M, Toyoshima Y, Tanaka S, Shiota K, Kitamura T, Fujita T, Ezaki O, Aizawa S, Kadowaki T et al (1999) PPAR gamma mediates high-fat diet-induced adipocyte hypertrophy and insulin resistance. Mol Cell 4:597-609

Lai CF, Cheng SL (2002) Signal transductions induced by bone morphogenetic protein-2 and transforming growth factor-beta in normal human osteoblastic cells. J Biol Chem 277:15514-15522

Langenfeld EM, Kong Y, Langenfeld J (2005) Bone morphogenetic protein-2-induced transformation involves the activation of mammalian target of rapamycin. Mol Cancer Res 3:679-684

Liao QC, Li YL, Qin YF, Quarles LD, Xu KK, Li R, Zhou HH, Xiao ZS (2008) Inhibition of adipocyte differentiation by phytoestrogen genistein through a potential downregulation of extracellular signalregulated kinases 1/2 activity. J Cell Biochem 104:1853-1864

Lou J, Tu Y, Li S, Manske PR (2000) Involvement of ERK in BMP-2 induced osteoblastic differentiation of mesenchymal progenitor cell line C3H10T1/2. Biochem Biophys Res Commun 268:757762

Marcus R, Feldman D, Nelson DA, Rosen CJ (2008) Osteoporosis. Elsevier Academic Press, San Diego, CA
Massague J (1998) TGF-beta signal transduction. Annu Rev Biochem 67:753-791

Matsubara T, Kida K, Yamaguchi A, Hata K, Ichida F, Meguro H, Aburatani H, Nishimura R, Yoneda T (2008) BMP2 regulates Osterix through Msx2 and Runx2 during osteoblast differentiation. J Biol Chem 283:29119-29125

Nohe A, Petersen NO (2007) Image correlation spectroscopy. Sci STKE 2007:pl7

Nohe A, Keating E, Loh C, Underhill MT, Petersen NO (2004) Caveolin-1 isoform reorganization studied by image correlation spectroscopy. Faraday Discuss 126:185-195, discussion 245-54

Noth U, Tuli R, Seghatoleslami R, Howard M, Shah A, Hall DJ, Hickok NJ, Tuan RS (2003) Activation of p38 and Smads mediates BMP-2 effects on human trabecular bone-derived osteoblasts. Exp Cell Res 291:201-211

Saldanha S, Bragdon B, Moseychuk O, Bonor J, Dhurjati P, Nohe A (2013) Caveolae regulate smad signaling as verified by novel imaging and system biology approaches. J Cell Physiol 228(5):1060-1069

Schulz TJ, Tseng YH (2009) Emerging role of bone morphogenetic proteins in adipogenesis and energy metabolism. Cytokine Growth Factor Rev 20:523-531

Seale P, Kajimura S, Yang W, Chin S, Rohas LM, Uldry M, Tavernier G, Langin D, Spiegelman BM (2007) Transcriptional control of brown fat determination by PRDM16. Cell Metab 6:38-54

Seale P, Bjork B, Yang W, Kajimura S, Chin S, Kuang S, Scime A, Devarakonda S, Conroe HM, Erdjument-Bromage H, Tempst P, Rudnicki MA, Beier DR, Spiegelman BM (2008) PRDM16 controls a brown fat/skeletal muscle switch. Nature 454:961-967

Senta H, Park H, Bergeron E, Drevelle O, Fong D, Leblanc E, Cabana F, Roux S, Grenier G, Faucheux N (2009) Cell responses to bone morphogenetic proteins and peptides derived from them: biomedical applications and limitations. Cytokine Growth Factor Rev 20:213-222

Sieber C, Kopf J, Hiepen C, Knaus P (2009) Recent advances in BMP receptor signaling. Cytokine Growth Factor Rev 20:343-355

Siersbaek R, Nielsen R, Mandrup S (2010) PPARgamma in adipocyte differentiation and metabolism-novel insights from genome-wide studies. FEBS Lett 584:3242-3249

Sugimori K, Matsui K, Motomura H, Tokoro T, Wang J, Higa S, Kimura T, Kitajima I (2005) BMP-2 prevents apoptosis of the N1511 chondrocytic cell line through PI3K/Akt-mediated NFkappaB activation. J Bone Miner Metab 23:411-419

ten Dijke P, Ichijo H, Franzén P, Schulz P, Saras J, Toyoshima H, Heldin CH, Miyazono K (1993) Activin receptor-like kinases: a novel subclass of cell-surface receptors with predicted serine/ threonine kinase activity. Oncogene 8:2879-2887

Tseng Y-H, He T-C (2007) Bone morphogenetic proteins and adipocyte differentiation. Cellscience Rev 3(3):342-360

Viñals F, López-Rovira T, Rosa JL, Ventura F (2002) Inhibition of $\mathrm{PI} 3 \mathrm{~K} / \mathrm{p} 70 \mathrm{~S} 6 \mathrm{~K}$ and $\mathrm{p} 38 \mathrm{MAPK}$ cascades increases osteoblastic differentiation induced by BMP-2. FEBS Lett 510:99-104 